\title{
Predictors of postoperative complications in elderly and oldest old patients with gastric cancer
}

\author{
Takehiro Takama $\cdot$ Keiichi Okano • \\ Akihiro Kondo • Shintaro Akamoto • \\ Masao Fujiwara $\cdot$ Hisashi Usuki $\cdot$ Yasuyuki Suzuki
}

Received: 15 November 2013/Accepted: 5 May 2014/Published online: 30 May 2014

(C) The International Gastric Cancer Association and The Japanese Gastric Cancer Association 2014

\begin{abstract}
Background The incidence of gastric cancer has been increasing among elderly persons in Japan. This study aimed to clarify risk factors for postoperative complications in oldest old patients with gastric cancer.

Methods One-hundred ninety patients more than 75 years old with gastric cancer underwent gastrectomy between 2000 and 2011. Patients were classified into two groups: group A included 29 patients who were 85 years or older (oldest old patients), and group B included 161 patients who were 75-84 years of age. Perioperative parameters associated with complications were compared in each group.

Results The preoperative estimated glomerular filtration rate was significantly lower in group A $(p=0.03)$. The two groups significantly differed in performance status $(p=0.018)$. Patients in group A received a lesser extent of lymph node dissection and had fewer lymph nodes excised. As a result, the duration of the operation was significantly shorter in group A. There were no significant differences in the frequency or grade of total complications or mortality between the two groups. Operative hemorrhage ( $>300 \mathrm{ml})$ and Hiroshima POSSUM (predicted morbidity risk $>40$ ) were risk factors in both groups $\mathrm{A}$ and $\mathrm{B}$; the risk factors of preoperative serum albumin level and prognostic nutritional index (PNI) were specific to group A.
\end{abstract}

Electronic supplementary material The online version of this article (doi:10.1007/s10120-014-0387-6) contains supplementary material, which is available to authorized users.

T. Takama $\cdot$ K. Okano $(\bowtie) \cdot$ A. Kondo $\cdot$ S. Akamoto

M. Fujiwara · H. Usuki · Y. Suzuki

Department of Gastroenterological Surgery, Faculty of

Medicine, Kagawa University, 1750-1, Ikenobe, Miki-cho,

Kita-gun, Kagawa 761-0793, Japan

e-mail: kokano@med.kagawa-u.ac.jp
Conclusions Adjustments to the extent of surgery among oldest old patients most likely reduces the incidence of postoperative complications in this group. Preoperative serum albumin level and PNI are significant predictors of postoperative complications in oldest old patients with gastric cancer.

Keywords Postoperative complications - Elderly · Oldest old · Gastric cancer

\section{Introduction}

The number of elderly individuals (aged 65 years or older) has rapidly increased in Japan. In 1994, elderly persons accounted for $14 \%$ of the Japanese population. By 2013, this figure had increased to $25 \%$, including the $11.9 \%$ of the population in late-stage old age ( $\geq 75$ years old) [1]. This increase reflects the aging society of Japan, in which 1 in 4 persons are elderly and 1 in 9 persons are late-stage elderly. In gerontology, individuals who are at least 85 years old are often called the oldest old. Twenty percent of gastric cancer patients in Japan are more than 80 years old. Elderly patients have a higher incidence of postoperative complications that are caused by reduced physiological function. Additionally, rates of underlying diseases are higher among elderly patients, meaning that complications may tend to be more serious [2, 3]. Consequently, postoperative complications among the elderly may lead to prolonged hospitalization, increased medical costs, and wasteful uses of human resources. To prevent postoperative complications in the elderly, it is important to evaluate the risks of postoperative complications according to the overall preoperative status and to vary postoperative care depending on the type of surgery and the specifics of the case. The present study was conducted to clarify factors associated 
with postoperative complications among late-stage elderly patients with gastric cancer, and particularly among oldest old patients with gastric cancer (aged $\geq 85$ years).

\section{Patients and methods}

One-hundred ninety patients more than 75 years old with gastric cancer underwent gastrectomy at the Department of Gastroenterological Surgery, Kagawa University, between January 2000 and December 2011. Patients were classified into two groups: group A included the 29 patients who were 85 years or older (oldest old patients), and group B included the 161 patients who were 75-84 years of age.

These two groups were examined and compared in terms of sex; past history (the presence or absence of diabetes mellitus, ischemic heart disease, and lung disease); body mass index; preoperative serum albumin level; prognostic nutritional index (PNI), as proposed by Onodera et al. $[\mathrm{PNI}=$ serum albumin $(\mathrm{g} / \mathrm{dl})+$ total peripheral lymphocyte count $\left(/ \mathrm{mm}^{3}\right)$ ] [4]; respiratory function [percent vital capacity $(\% \mathrm{VC})$; forced expiratory volume (FEV) $1.0 \%$ ]; renal function [estimated glomerular filtration rate (eGFR)] [5]; the type of surgery performed; lymph node excision (the degree of lymph node dissection and the number of excised lymph nodes); bleeding; surgery time; disease stage; Physiological and Operative Severity Score for the Enumeration of Mortality and Morbidity (POSSUM) for comprehensive risk assessment; Hiroshima POSSUM (H-POSSUM; developed on the basis of POSSUM for Japanese patients) [6-11]; performance status (PS) [Eastern Cooperative Oncology Group (ECOG)] [12]; and postoperative complications. We applied the new American College of Surgeons National Surgical Quality Improvement Program (ACS NSQIP) standard to define postoperative complications [13, 14]. Surgical complications were graded according to the Clavien-Dindo classification for patients with postoperative complications (grade II or greater) [15-17].

To analyze the risk factors for complications, patients in groups A and B were separated into those who did and did not develop complications. The degree of lymph node dissection was based on the Japanese classification of gastric cancers, 13th edition, and the stage of disease was based on the Japanese classification of gastric cancers, 14th edition. This clinical cohort study was approved by the Dean of the Faculty of Medicine, Kagawa University.

\section{Statistics}

The chi-square test, $t$ test (Student's or Welch's), and Mann-Whitney $U$ test were used to assess statistical significance. Survival curves were estimated using the Kaplan-Meier method, and survival differences were assessed using the log-rank test. The 1-, 3-, and 5-year survival rates were estimated using life tables. Logistic regression models were used for multivariate analyses. The multivariate models included all risk factors that were significantly associated with complications in univariate models $(p<0.05)$. Throughout our analysis, values of $p<0.05$ were considered statistically significant. All statistical analyses were performed using SAS 8.2 (SAS Institute, Cary, NC, USA).

\section{Results}

Patient characteristics are summarized in Table 1. Considering preoperative tests, preoperative eGFR in group A was significantly lower than that in group B. Considering surgical procedures, there were significantly fewer patients who underwent total gastrectomy in group A than there were in group B $(p=0.032)$. Patients in group A received a lesser degree of lymph node dissection $(p=0.007)$ and had fewer lymph nodes excised $(p=0.018)$. As a result, operation times were significantly shorter in group A $(p=0.003)$. As assessed using POSSUM and H-POSSUM, predicted morbidity and mortality risks did not differ significantly between the two groups. However, the two groups differed significantly in terms of performance status (PS; $p=0.018)$. In group A, 2 patients $(6.9 \%)$ had PSO, 18 patients $(62.1 \%)$ had PS1, and 4 patients $(13.8 \%)$ had PS2. In group B, 33 patients (20.5\%) had PS0, 68 patients (42.2\%) had PS1, and 51 patients (31.7\%) had PS2.

In regard to postoperative complications, we observed no significant differences in the frequencies or characteristics of the complications between the two groups (Table 2). Eight patients (5\%) developed pancreatic fistula in group B, of which $6(3.7 \%)$ had grade B pancreatic fistula, and $2(1.2 \%)$ had grade $\mathrm{C}$ pancreatic fistula, according to the International Study Group of Pancreatic Fistula (ISGPF) classification. No patients developed pancreatic fistula (ISGPF grade B or C) in group A. An intraabdominal abscess was documented in 5 patients (3.1\%) in group B; no patients developed intraabdominal abscess in group A. However, there were no significant differences in pancreatic fistulae or intraabdominal abscesses between the two groups. Group A did include a significantly larger proportion of patients who experienced postoperative delirium (41.4\% in group A vs. $10.6 \%$ in group $\mathrm{B} ; p=0.0009)$. However, postoperative delirium was excluded from the major study endpoints concerning complications.

Surgical complications were graded according to the Clavien-Dindo classification. Fifty-six $(29.5 \%)$ patients 
Table 1 Comparison of patient characteristics

\begin{tabular}{|c|c|c|c|}
\hline & $\begin{array}{l}\text { Group A } \\
(n=29)\end{array}$ & $\begin{array}{l}\text { Group B } \\
(n=161)\end{array}$ & $p$ value \\
\hline \multicolumn{4}{|l|}{ Gender } \\
\hline Female & $13(44.8 \%)$ & $47(29.2 \%)$ & \multirow[t]{2}{*}{0.095} \\
\hline Male & $16(55.2 \%)$ & $114(70.8 \%)$ & \\
\hline BMI & $21.3 \pm 3.3$ & $22.1 \pm 3.2$ & 0.210 \\
\hline \multicolumn{4}{|l|}{ Past history } \\
\hline Ischemic heart disease & $6(20.7 \%)$ & $21(13.0 \%)$ & 0.278 \\
\hline Diabetes mellitus & $3(10.3 \%)$ & $29(18.0 \%)$ & 0.456 \\
\hline Lung disease & $6(20.7 \%)$ & $37(23.0 \%)$ & 0.786 \\
\hline \multicolumn{4}{|l|}{ Nutrition } \\
\hline Serum albumin $(\mathrm{g} / \mathrm{dl})$ & $3.20 \pm 0.60$ & $3.42 \pm 0.58$ & 0.097 \\
\hline PNI & $38.55 \pm 7.31$ & $41.28 \pm 7.44$ & 0.081 \\
\hline \multicolumn{4}{|l|}{ Respiratory function } \\
\hline$\% \mathrm{VC}$ & $85.7 \pm 18.7$ & $89.8 \pm 17.4$ & 0.273 \\
\hline FEV 1.0 & $77.1 \pm 13.2$ & $75.9 \pm 14.2$ & 0.585 \\
\hline \multicolumn{4}{|l|}{ Renal function } \\
\hline eGFR & $52.7 \pm 14.0$ & $59.8 \pm 19.2$ & 0.033 \\
\hline \multicolumn{4}{|l|}{ Operation } \\
\hline \multicolumn{4}{|l|}{ Procedures } \\
\hline TG & $7(24.1 \%)$ & $64(39.8 \%)$ & \multirow[t]{3}{*}{0.038} \\
\hline DG or PG & $17(58.6 \%)$ & $95(59.0 \%)$ & \\
\hline Others & $5(17.3 \%)$ & $2(1.2 \%)$ & \\
\hline Time (min) & $246 \pm 80$ & $297 \pm 87$ & 0.004 \\
\hline Bleeding (ml) & $411 \pm 621$ & $428 \pm 360$ & 0.064 \\
\hline \multicolumn{4}{|l|}{ Lymph node dissection } \\
\hline D0 or D1 & $15(51.7 \%)$ & $43(26.7 \%)$ & \multirow[t]{2}{*}{0.007} \\
\hline$>\mathrm{D} 1$ & $14(48.3 \%)$ & $118(73.3 \%)$ & \\
\hline $\begin{array}{l}\text { No. of removed lymph } \\
\text { nodes }\end{array}$ & $14.5 \pm 10.4$ & $21.2 \pm 12.2$ & 0.006 \\
\hline \multicolumn{4}{|l|}{ pStage } \\
\hline I or II & $21(72.4 \%)$ & $109(67.7 \%)$ & \multirow[t]{2}{*}{0.615} \\
\hline III or IV & $8(27.6 \%)$ & $52(32.3 \%)$ & \\
\hline \multicolumn{4}{|l|}{ POSSUM } \\
\hline Predicted morbidity risk & $50.9 \pm 18.1 \%$ & $49.4 \pm 19.6 \%$ & 0.637 \\
\hline Predicted mortality risk & $12.2 \pm 7.3 \%$ & $12.4 \pm 9.3 \%$ & 0.655 \\
\hline \multicolumn{4}{|l|}{ Hiroshima POSSUM } \\
\hline Predicted morbidity risk & $33.7 \pm 14.6 \%$ & $33.9 \pm 15.7 \%$ & 0.916 \\
\hline Predicted mortality risk & $2.6 \pm 1.8 \%$ & $2.8 \pm 3.1 \%$ & 0.542 \\
\hline \multicolumn{4}{|l|}{ Performance status } \\
\hline 0 & $2(6.9 \%)$ & $33(20.5 \%)$ & 0.018 \\
\hline 1 & $18(62.1 \%)$ & $68(42.2 \%)$ & \\
\hline 2 & $4(13.8 \%)$ & $51(31.7 \%)$ & \\
\hline 3 & $3(10.3 \%)$ & $6(3.7 \%)$ & \\
\hline 4 & 0 & 0 & \\
\hline
\end{tabular}

$T G$ total gastrectomy, $D G$ distal gastrectomy, $P G$ proximal gastrectomy, POSSUM Physiological and Operative Severity Score for the Enumeration of Mortality and Morbidity

had at least one complication that was classified as grade II or greater: 37 patients $(19.5 \%)$ had grade II complications (which require drug therapy, such as antibiotics), 12
Table 2 Postoperative mortality and morbidity

\begin{tabular}{llll}
\hline & $\begin{array}{l}\text { Group A } \\
(n=29)\end{array}$ & $\begin{array}{l}\text { Group B } \\
(n=161)\end{array}$ & $p$ value \\
\hline Mortality & $1(3.4 \%)$ & $3(1.9 \%)$ & 0.877 \\
Morbidity & $12(41.4 \%)$ & $55(34.2 \%)$ & 0.454 \\
Respiratory disease & $5(17.2 \%)$ & $16(9.9 \%)$ & 0.248 \\
Ileus/stenosis & $4(13.8 \%)$ & $15(9.3 \%)$ & 0.687 \\
Wound infection & $2(6.9 \%)$ & $11(6.8 \%)$ & 0.699 \\
Pancreatitis/pancreatic & 0 & $8(5.0 \%)$ & 0.469 \\
$\quad$ fistula & $1(3.4 \%)$ & $6(3.7 \%)$ & 0.644 \\
Cardiovascular disease & 0 & $5(3.1 \%)$ & 0.740 \\
Intraabdominal & 0 & $4(2.5 \%)$ & 0.740 \\
$\quad$ abscess & $1(3.4 \%)$ & $3(1.9 \%)$ & 0.946 \\
Anastomotic leakage & 0 & $2(1.2 \%)$ & 0.946 \\
Sepsis & $1(3.4 \%)$ & $3(1.9 \%)$ & 0.877 \\
Bleeding & $1(3.4 \%)$ & $10(6.2 \%)$ & - \\
Other infections & $3(10.3 \%)$ & & \\
Others & $1(3.4 \%)$ & $3(1.9 \%)$ & \\
Clavien-Dindo classification (grade II or greater) & $31(19.3 \%)$ & 0.068 \\
Grade II & $6(20.6 \%)$ & $9(5.6 \%)$ & \\
Grade IIIa & $1(3.4 \%)$ & $2(1.2 \%)$ & \\
Grade IIIb & 0 & $1(0.6 \%)$ & \\
Grade IVa & $1(3.4 \%)$ & & \\
Grade IVb & $1(3.4 \%)$ & 0 & \\
Grade V & & & \\
\hline
\end{tabular}

patients (6.4\%) had grade III complications (which require invasive therapy), and 3 patients $(1.6 \%)$ had grade IV complications (which involve organ dysfunction and stays in the intensive care unit). A grade $\mathrm{V}$ complication (death) occurred in 4 patients $(2.1 \%)$. There was no significant difference in Clavien-Dindo grades between the two groups (Table 2).

Subgroup analyses of risk factors for postoperative complications are presented in Table 3. In group A, univariate analyses showed that serum albumin $(<3.5 \mathrm{~g} / \mathrm{dl})$, PNI $(<40)$, operative hemorrhage $(>300 \mathrm{ml})$, and H-POSSUM predicted morbidity risk $(\geq 40)$ were significantly associated with operative morbidity. In group B, diabetes mellitus, operative hemorrhage $(\geq 300 \mathrm{ml})$, and H-POSSUM predicted morbidity risk $(\geq 40)$ were significantly associated with operative morbidity. In the overall study cohort (group A + B), operative hemorrhage ( $\geq 300 \mathrm{ml}$ ), POSSUM predicted mortality risk $(\geq 10)$, and H-POSSUM predicted morbidity risk $(\geq 40)$ were significantly associated with operative morbidity. Accordingly, preoperative serum albumin and PNI were the significant predictors of postoperative complications that were specific to group A. In contrast, the risk factors operative hemorrhage $(>300 \mathrm{ml})$ and H-POSSUM predicted morbidity risk $(>40)$ were common to all subgroups (groups $\mathrm{A}, \mathrm{B}$, and $\mathrm{A}+\mathrm{B}$ ) 
Table 3 Comparison of patient characteristics subdivided according to the presence or absence of complication

\begin{tabular}{|c|c|c|c|c|c|c|c|c|c|}
\hline \multirow[t]{2}{*}{ Complication } & \multicolumn{2}{|c|}{ Group A ( $\geq 85$ years) } & \multirow[t]{2}{*}{$p$ value } & \multicolumn{2}{|c|}{ Group B (75-84 years) } & \multirow[t]{2}{*}{$p$ value } & \multicolumn{2}{|c|}{ All ( $\geq 75$ years) } & \multirow[t]{2}{*}{$p$ value } \\
\hline & $\begin{array}{l}- \\
n=17\end{array}$ & $\begin{array}{l}+ \\
n=12\end{array}$ & & $\begin{array}{l}- \\
n=106\end{array}$ & $\begin{array}{l}+ \\
n=55\end{array}$ & & $\begin{array}{l}- \\
n=123\end{array}$ & $\begin{array}{l}+ \\
n=67\end{array}$ & \\
\hline \multicolumn{10}{|l|}{ Gender } \\
\hline Female & $6(35.3 \%)$ & $7(58.3 \%)$ & 0.219 & $35(33.0 \%)$ & $12(21.8 \%)$ & 0.138 & $41(33.3 \%)$ & $19(28.4 \%)$ & 0.5171 \\
\hline Male & $11(64.7 \%)$ & $5(41.7 \%)$ & & $71(67.0 \%)$ & $43(78.2 \%)$ & & $82(66.7 \%)$ & $48(71.6 \%)$ & \\
\hline \multicolumn{10}{|l|}{ Past history } \\
\hline Ischemic heart disease & $5(29.4 \%)$ & $1(8.3 \%)$ & 0.360 & $11(10.4 \%)$ & $10(18.2 \%)$ & 0.163 & $16(13.0 \%)$ & $11(16.4 \%)$ & 0.5217 \\
\hline Diabetes mellitus & $2(11.8 \%)$ & $1(8.3 \%)$ & 0.749 & $14(13.2 \%)$ & $15(27.3 \%)$ & 0.028 & $16(13.0 \%)$ & $16(23.9 \%)$ & 0.0684 \\
\hline Lung disease & $5(29.4 \%)$ & $1(8.3 \%)$ & 0.360 & $24(22.6 \%)$ & $13(23.6 \%)$ & 0.887 & $29(23.6 \%)$ & $14(20.9 \%)$ & 0.7200 \\
\hline \multicolumn{10}{|l|}{ Nutrition } \\
\hline \multicolumn{10}{|l|}{ Serum albumin $(\mathrm{g} / \mathrm{dl})$} \\
\hline$\geq 3.5$ & $9(52.9 \%)$ & $1(8.3 \%)$ & 0.019 & $52(49.1 \%)$ & $28(50.9 \%)$ & 0.869 & $61(49.6 \%)$ & $29(43.3 \%)$ & 0.449 \\
\hline$<3.5$ & $8(47.1 \%)$ & $11(91.7 \%)$ & & $54(50.9 \%)$ & $27(49.1 \%)$ & & $62(50.4 \%)$ & $38(56.7 \%)$ & \\
\hline \multicolumn{10}{|l|}{ PNI } \\
\hline$\geq 40$ & $11(64.7 \%)$ & $1(8.3 \%)$ & 0.005 & $54(50.9 \%)$ & $35(36.6 \%)$ & 0.110 & $65(52.8 \%)$ & $36(53.7 \%)$ & 0.873 \\
\hline$<40$ & $5(29.4 \%)$ & $10(83.3 \%)$ & & $43(40.6 \%)$ & $15(27.3 \%)$ & & $48(39.0 \%)$ & $25(37.3 \%)$ & \\
\hline \multicolumn{10}{|l|}{ Respiratory function } \\
\hline \multicolumn{10}{|l|}{$\% \mathrm{VC}$} \\
\hline$\geq 80$ & $13(76.5 \%)$ & $5(41.7 \%)$ & 0.219 & $72(67.9 \%)$ & $41(74.5 \%)$ & 0.349 & $85(69.1 \%)$ & $46(68.7 \%)$ & 0.734 \\
\hline$<80$ & $4(23.5 \%)$ & $5(41.7 \%)$ & & $32(30.2 \%)$ & $12(21.8 \%)$ & & $36(29.3 \%)$ & $17(25.4 \%)$ & \\
\hline \multicolumn{10}{|l|}{ FEV 1.0} \\
\hline$\geq 70$ & $11(64.7 \%)$ & $9(75 \%)$ & 0.204 & $76(71.7 \%)$ & $35(63.6 \%)$ & 0.259 & $87(70.7 \%)$ & $44(65.7 \%)$ & 0.604 \\
\hline$<70$ & $6(35.3 \%)$ & $1(8.3 \%)$ & & $25(23.6 \%)$ & $18(32.7 \%)$ & & $31(25.2 \%)$ & $19(28.4 \%)$ & \\
\hline \multicolumn{10}{|l|}{ Renal function } \\
\hline \multicolumn{10}{|l|}{ eGFR } \\
\hline$\geq 60$ & $4(23.5 \%)$ & $2(16.7 \%)$ & 1.000 & $53(50 \%)$ & $20(36.4 \%)$ & 0.133 & $57(46.3 \%)$ & $22(32.8 \%)$ & 0.090 \\
\hline$<60$ & $13(76.5 \%)$ & $10(83.3 \%)$ & & $53(50 \%)$ & $35(63.6 \%)$ & & $66(53.7 \%)$ & $45(67.2 \%)$ & \\
\hline \multicolumn{10}{|l|}{ Operative factor } \\
\hline \multicolumn{10}{|l|}{ Procedures } \\
\hline TG & $5(29.4 \%)$ & $2(16.7 \%)$ & 0.634 & $40(37.7 \%)$ & $25(45.5 \%)$ & & $45(36.6 \%)$ & $27(40.3 \%)$ & 0.7061 \\
\hline DG or PG & $10(58.5 \%)$ & $9(75.0 \%)$ & & $64(60.4 \%)$ & $30(54.6 \%)$ & 0.318 & $74(60.2 \%)$ & $39(58.2 \%)$ & \\
\hline Others & $2(11.8 \%)$ & $1(8.3 \%)$ & & $2(1.9 \%)$ & $0(0 \%)$ & & $4(3.3 \%)$ & $1(1.5 \%)$ & \\
\hline \multicolumn{10}{|l|}{ Lymph node dissection } \\
\hline D0 or D1 & $7(41.2 \%)$ & $8(66.7 \%)$ & 0.329 & $30(28.3 \%)$ & $13(23.6 \%)$ & 0.526 & $37(30.1 \%)$ & $21(31.3 \%)$ & 0.870 \\
\hline$>\mathrm{D} 1$ & $10(58.8 \%)$ & $4(33.3 \%)$ & & $76(71.7 \%)$ & $42(76.4 \%)$ & & $86(69.9 \%)$ & $46(68.7 \%)$ & \\
\hline Time (min) & & & & & & & & & \\
\hline$\geq 300$ & $6(35.3 \%)$ & $3(25 \%)$ & 0.694 & $46(43.4 \%)$ & $29(52.7 \%)$ & 0.318 & $52(42.3 \%)$ & $32(47.8 \%)$ & 0.541 \\
\hline$<00$ & $11(64.7 \%)$ & $9(75 \%)$ & & $60(56.6 \%)$ & $26(47.3 \%)$ & & $71(57.7 \%)$ & $35(52.2 \%)$ & \\
\hline Bleeding (ml) & & & & & & & & & \\
\hline$\geq 300$ & $3(17.6 \%)$ & $7(58.3 \%)$ & 0.046 & $51(48.1 \%)$ & $36(65.5 \%)$ & 0.046 & $54(43.9 \%)$ & $43(64.3 \%)$ & 0.010 \\
\hline$<300$ & $14(82.4 \%)$ & $5(41.7 \%)$ & & $55(51.9 \%)$ & $19(34.5 \%)$ & & $69(56.1 \%)$ & $24(35.8 \%)$ & \\
\hline No. of removed lymph & odes & & & & & & & & \\
\hline$\geq 16$ & $9(52.9 \%)$ & $3(25.0 \%)$ & 0.253 & $68(64.2 \%)$ & $33(60 \%)$ & 0.611 & $77(62.6 \%)$ & $36(53.7 \%)$ & 0.3506 \\
\hline$<16$ & $8(47.1 \%)$ & $8(66.7 \%)$ & & $38(35.8 \%)$ & $22(40 \%)$ & & $46(37.4 \%)$ & $30(44.8 \%)$ & \\
\hline pStage & & & & & & & & & \\
\hline I or II & $14(82.4 \%)$ & $7(58.3 \%)$ & 0.316 & $69(65.1 \%)$ & $40(72.7 \%)$ & 0.104 & $83(67.5 \%)$ & $47(70.1 \%)$ & 0.7461 \\
\hline III or IV & $3(17.7 \%)$ & $5(41.7 \%)$ & & $37(34.9 \%)$ & $15(27.3 \%)$ & & $40(32.5 \%)$ & $20(29.9 \%)$ & \\
\hline POSSUM: & & & & & & & & & \\
\hline
\end{tabular}


Table 3 continued

\begin{tabular}{|c|c|c|c|c|c|c|c|c|c|}
\hline \multirow[t]{2}{*}{ Complication } & \multicolumn{2}{|c|}{ Group A ( $\geq 85$ years) } & \multirow[t]{2}{*}{$p$ value } & \multicolumn{2}{|c|}{ Group B (75-84 years) } & \multirow[t]{2}{*}{$p$ value } & \multicolumn{2}{|c|}{ All ( $\geq 75$ years) } & \multirow[t]{2}{*}{$p$ value } \\
\hline & $\begin{array}{l}- \\
n=17\end{array}$ & $\begin{array}{l}+ \\
n=12\end{array}$ & & $\begin{array}{l}- \\
n=106\end{array}$ & $\begin{array}{l}+ \\
n=55\end{array}$ & & $\begin{array}{l}- \\
n=123\end{array}$ & $\begin{array}{l}+ \\
n=67\end{array}$ & \\
\hline \multicolumn{10}{|c|}{ Predicted morbidity risk } \\
\hline$\geq 40$ & $9(52.9 \%)$ & $8(66.7 \%)$ & 0.703 & $64(60.4 \%)$ & $37(67.3 \%)$ & 0.492 & $73(59.3 \%)$ & $45(67.2 \%)$ & 0.348 \\
\hline$<40$ & $8(47.1 \%)$ & $4(33.3 \%)$ & & $42(36.9 \%)$ & $18(32.7 \%)$ & & $50(40.7 \%)$ & $22(32.8 \%)$ & \\
\hline \multicolumn{10}{|c|}{ Predicted mortality risk } \\
\hline$\geq 10$ & $7(41.2 \%)$ & $7(58.3 \%)$ & 0.462 & $44(41.5 \%)$ & $31(56.4 \%)$ & 0.096 & $51(41.5 \%)$ & $38(56.7 \%)$ & 0.049 \\
\hline$<10$ & $10(58.8 \%)$ & $5(41.7 \%)$ & & $62(58.5 \%)$ & $24(43.6 \%)$ & & $72(58.5 \%)$ & $29(43.3 \%)$ & \\
\hline \multicolumn{10}{|c|}{ Hiroshima POSSUM: } \\
\hline \multicolumn{10}{|c|}{ Predicted morbidity risk } \\
\hline$\geq 40$ & $2(11.8 \%)$ & $6(50 \%)$ & 0.038 & $26(24.5 \%)$ & $25(45.5 \%)$ & 0.012 & $28(22.8 \%)$ & $31(46.3 \%)$ & 0.001 \\
\hline$<40$ & $15(88.2 \%)$ & $6(50 \%)$ & & $80(75.5 \%)$ & $30(54.5 \%)$ & & $95(77.2 \%)$ & $36(53.7 \%)$ & \\
\hline \multicolumn{10}{|c|}{ Predicted mortality risk } \\
\hline$\geq 4$ & $2(11.8 \%)$ & $5(41.7 \%)$ & 0.092 & $20(18.9 \%)$ & $12(21.8 \%)$ & 0.681 & $22(17.9 \%)$ & $17(25.4 \%)$ & 0.260 \\
\hline$<4$ & $15(88.2 \%)$ & $7(58.3 \%)$ & & $86(81.1 \%)$ & $43(78.2 \%)$ & & $101(82.1 \%)$ & $50(74.6 \%)$ & \\
\hline
\end{tabular}

Table 4 Comparison of patient characteristics subdivided according to the presence or absence of complications

\begin{tabular}{|c|c|c|c|c|c|c|}
\hline \multirow[t]{2}{*}{ Complication } & \multicolumn{2}{|l|}{ Group A } & \multirow[t]{2}{*}{$p$ value } & \multicolumn{2}{|l|}{ Group B } & \multirow[t]{2}{*}{$p$ value } \\
\hline & $\begin{array}{l}- \\
n=17\end{array}$ & $\begin{array}{l}+ \\
n=12\end{array}$ & & $\begin{array}{l}- \\
n=106\end{array}$ & $\begin{array}{l}+ \\
n=55\end{array}$ & \\
\hline \multicolumn{7}{|l|}{ Nutrition } \\
\hline Serum albumin $(\mathrm{g} / \mathrm{dl})$ & $3.47 \pm 0.35$ & $2.82 \pm 0.69$ & 0.008 & $3.39 \pm 0.60$ & $3.48 \pm 0.51$ & 0.333 \\
\hline PNI & $42.3 \pm 4.7$ & $33.1 \pm 7.2$ & $<0.001$ & $40.8 \pm 7.8$ & $42.1 \pm 6.5$ & 0.279 \\
\hline \multicolumn{7}{|l|}{ Respiratory function } \\
\hline$\% \mathrm{VC}$ & $88.8 \pm 13.4$ & $80.4 \pm 25.3$ & 0.344 & $89.3 \pm 18.4$ & $90.6 \pm 15.3$ & 0.655 \\
\hline FEV 1.0 & $74.1 \pm 13.6$ & $82.2 \pm 11.5$ & 0.339 & $77.1 \pm 13.9$ & $73.5 \pm 14.5$ & 0.165 \\
\hline \multicolumn{7}{|l|}{ Renal function } \\
\hline eGFR & $50.7 \pm 16.9$ & $55.4 \pm 8.6$ & 0.104 & $61.5 \pm 18.7$ & $56.3 \pm 19.9$ & 0.072 \\
\hline \multicolumn{7}{|l|}{ Operative factor } \\
\hline Time $(\min )$ & $248 \pm 88$ & $242 \pm 71$ & 0.823 & $289 \pm 87$ & $311 \pm 87$ & 0.143 \\
\hline Bleeding (ml) & $205 \pm 133$ & $702 \pm 893$ & 0.061 & $387 \pm 340$ & $507 \pm 387$ & 0.018 \\
\hline $\begin{array}{l}\text { No. of removed lymph } \\
\text { nodes }\end{array}$ & $17.4 \pm 11.2$ & $10.2 \pm 7.6$ & 0.099 & $21.3 \pm 12.2$ & $21.0 \pm 12.5$ & 0.784 \\
\hline \multicolumn{7}{|l|}{ POSSUM: } \\
\hline Predicted morbidity risk & $48.1 \pm 16.4$ & $54.9 \pm 20.3$ & 0.334 & $47.7 \pm 19.7$ & $52.7 \pm 19.3$ & 0.135 \\
\hline Predicted mortality risk & $10.8 \pm 6.0$ & $14.3 \pm 8.6$ & 0.209 & $11.8 \pm 9.2$ & $13.6 \pm 9.5$ & 0.133 \\
\hline \multicolumn{7}{|l|}{ Hiroshima POSSUM: } \\
\hline Predicted morbidity risk & $30.0 \pm 11.4$ & $38.9 \pm 17.3$ & 0.107 & $32.6 \pm 15.9$ & $36.2 \pm 15.1$ & 0.107 \\
\hline Predicted mortality risk & $2.3 \pm 1.6$ & $3.0 \pm 2.1$ & 0.463 & $2.6 \pm 2.8$ & $3.2 \pm 3.7$ & 0.150 \\
\hline
\end{tabular}

(Table 3). Our multivariate logistic regression analysis did not identify any significant independent risk factors.

In group A, patients with complications had significantly lower serum albumin levels and PNI. In group B, patients with complications experienced significantly greater operative hemorrhage (Table 4).
For univariate predictions of postoperative complications, the optimum cutoff for serum albumin levels was $2.9 \mathrm{~g} / \mathrm{dl}$, and the associated area under the receiver operating characteristic curve was 0.826 . Analogous values for PNI were $38.1 \mathrm{~g} / \mathrm{dl}$ and 0.898 , respectively. When cases were partitioned according to these cutoffs, the resulting 


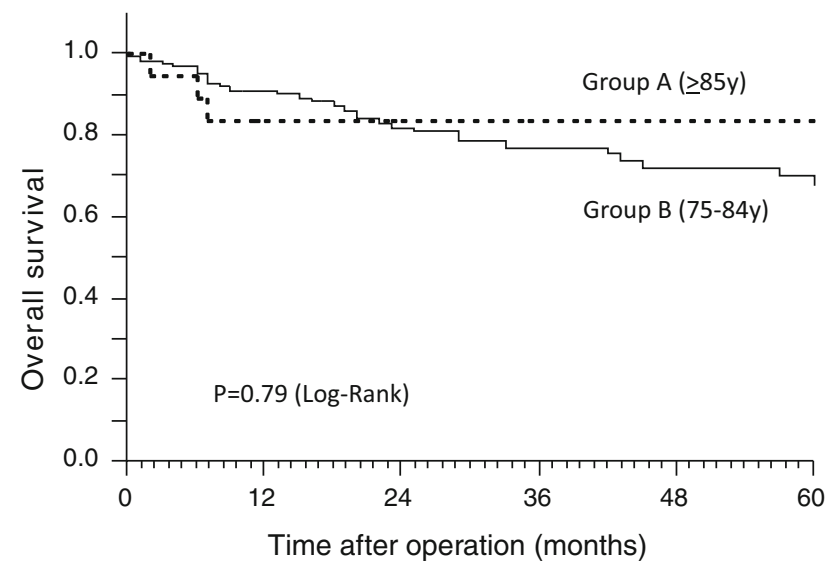

Fig. 1 Kaplan-Meier survival curves after surgery for patients in group A (age $\geq 85$ years) and group B (age 75-84 years). There was no significant difference in prognosis between the two groups (logrank test, $\mathrm{p}=0.79) . y$ years

groups had significantly different incidences of complications. Further, we observed that respiratory complications developed in many of the cases falling below the cutoff values for both serum albumin level and PNI (supplemental material).

Actuarial 1-, 3-, and 5-year postoperative survival rates were $83.8 \%, 83.8 \%$, and $83.8 \%$ in group A, and $91.2 \%$, $77.3 \%$, and $67.8 \%$ in group $\mathrm{B}$, respectively. Overall, the mean observation period was 46 months. The postoperative prognoses did not differ significantly between group A and group B (log-rank test, $p=0.79$; Fig. 1).

\section{Discussion}

Recently, the number of surgical interventions in the elderly has been rapidly increasing in Japan. Although several reports have indicated that the incidence of postoperative complications increases in elderly patients, the applicability of these results to older patients with gastric cancer is arguably limited [2, 3, 18, 19]. In this series, the incidence of complications in the group of patients $\geq 85$ years old (the oldest old group) was not significantly higher than that in the group of 75- to 84-year-old patients (the elderly group). This result is likely to be explained by difference in the extents of the surgeries in these groups. When we compared the types of surgeries, the durations of surgeries, and the extents of lymph node excision, we found that less invasive surgeries appeared to be selected for patients in the oldest old group. Intraabdominal abscesses and pancreatic fistulae have been reported as major complications after gastrectomy. They are thought to be associated with lymph node dissection around the pancreas. Interestingly, no patients experienced these complications in the oldest old group, even though 8 patients
(5\%) developed pancreatic fistula and 5 patients $(3.1 \%)$ developed intraabdominal abscess in the elderly group. These findings suggest that, in clinical practice, surgeons may avoid lymph node dissection around the pancreas, particularly among the oldest old.

The two groups did differ significantly in terms of PS. In the elderly group, 33 patients $(20.5 \%)$ had PS0, 68 patients $(42.2 \%)$ had PS1, and 51 patients $(31.7 \%)$ had PS2. On the other hand, in the oldest old group, 2 patients $(6.9 \%)$ had PS0, 18 patients (62.1\%) had PS1, and only 4 patients (13.8\%) had PS2. Accordingly, in clinical practice, PS2 or greater may generally be considered a contraindication for surgical resection in oldest old patients with gastric cancer.

In our further analysis of the postoperative course, however, we found that $41.4 \%$ of the patients in the oldest old group experienced postoperative delirium. This value was significantly higher than that in the elderly group $(10.6 \%)$. Because postoperative delirium can cause unexpected medical accidents and may lead to prolonged hospitalization, our results reaffirm that the oldest old require substantial care postoperatively. It has been reported that $10-50 \%$ of elderly patients who undergo surgical treatment develop delirium postoperatively [20]. Postoperative delirium is a reversible and fluctuating acute brain syndrome characterized by changes in consciousness, orientation, attention, memory, sensory perception, thinking, emotion, and/or volition. This condition may lead to prolonged hospital stays, may be associated with an unfavorable prognosis, and may develop into dementia [21]. Although the mechanisms of delirium remain unclear, multiple factors are known to be involved [22]. Besides advanced age, a recent study showed that systemic stress and inflammatory response may play important roles in the development of this condition [23]. Therefore, it is important to reduce perioperative stress and inflammatory responses to minimize the occurrence of delirium in elderly patients.

Elderly persons tend to have a higher rate of suboptimal renal function because of age-related arteriosclerosis [5]. In the present study, preoperative eGFR was significantly lower in the oldest old group than it was in the elderly group. However, eGFR did not differ significantly between patients who did and did not experience complications. Thus, it appeared that renal function in itself might not have affected the incidence of complications. Prolonged surgery times and unnecessary hemorrhage may cause reduced renal blood flow and lead to postoperative renal dysfunction [24]. In this study, preoperative suboptimal renal function was not associated with postoperative renal dysfunction, presumably because less invasive surgeries had carefully been selected for the oldest old patients.

In this study, we found that serum albumin level and PNI [4, 19, 25, 26] were significant risk factors for 
postoperative complications (especially respiratory complications) following gastrectomy among oldest old patients with gastric cancer. The presence of a strong relationship between preoperative nutrition and postoperative complications has been demonstrated previously [4, 19, 25-27]. It has been reported that postoperative albumin levels and postoperative peripheral blood lymphocyte counts are useful for estimating postoperative pulmonary complications and wound infection [27, 28]. Previous studies have investigated the prognostic utility of a variety of other nutritional indexes [7-9]. In particular, the Onodera et al. [4] PNI has been used widely because this measure is easy to calculate. Onodera et al. [4] reported that patients with advanced gastrointestinal cancer were operable for PNIs $\geq 45$, were at risk or in a warning zone for PNIs 40-45, and were contraindicated for resection and anastomosis for PNIs $<40$. In the present study, however, the optimal PNI cutoff was 38.1 in the oldest old population, and only $2(13.3 \%)$ of the 15 patients with PNIs exceeding 38.1 experienced a postoperative complication. Therefore, the criteria proposed by Onodera et al. [4] may have been too stringent, particularly as a result of recent advances in postoperative management. Based on our results, serum albumin level and PNI should be carefully considered when selecting treatments for oldest old patients. Further, our results tend to suggest that less invasive surgeries should be indicated for patients with serum albumin levels below the $2.9 \mathrm{~g} / \mathrm{dl}$ cutoff or PNIs below the 38.1 cutoff. However, larger prospective analyses are necessary to validate this recommendation.

In the present study, the POSSUM and H-POSSUM predicted morbidity and mortality risks [6-11,29] did not significantly differ between the oldest old and elderly groups, or between patients who did and did not experience complications. Although multiple studies have reported that POSSUM was useful for laparotomy in the elderly and oldest old, most of these previous studies evaluated cases of emergency surgery [27, 30]. POSSUM [6-11, 29] is calculated on the basis of a physiological score that consists of 12 preoperative factors (age, cardiac function, respiratory status, blood pressure, pulse, consciousness, hemoglobin value, white cell count, urea level, sodium level, potassium level, and electrocardiogram results), as well as an operative severity score that consists of six surgery-related factors (type of surgery, number of procedures, bleeding, intraabdominal contaminated wound, malignant tumor, and emergency surgery). Naturally, many studies of elective surgery in an elderly population will fail to show large differences in the total POSSUM score or, indeed, either of its components. Moreover, preoperative overall status is always assessed in clinical practice, and the appropriateness of surgical procedures is partly based on this assessment; therefore, the patients who are actually selected for each surgical option tend to be somewhat homogeneous. Therefore, predictors of postoperative outcomes other than POSSUM may be quite valuable when considering elective surgery in an elderly patient. For example, nutritional parameters may provide important evidence.

Large Japanese and East Asian studies have reported operative mortality rates of less than $1 \%$ for gastrectomy in cases of gastric cancer $[31,32]$. In contrast, the UK Medical Research Council and the Dutch D1 vs. D2 trials identified operative mortality rates of $13 \%$ and $10 \%$, respectively, for gastrectomy with D2 lymphadenectomy $[33,34]$. A recent large audit in the UK still reported mortality rates in the region of $10 \%$ [35, 36]. Among patients $\geq 75$ years old, the 30 -day mortality rate for gastric cancer surgery was $12.8 \%$ in the Netherlands [37]. In contrast, operative mortality rates in the present study were $1.9 \%$ in the elderly (75-84 years old) and $3.4 \%$ in the oldest old ( $\geq 85$ years old). The most important difference between the East and West appears to be the different populations who undergo resection for gastric cancer [38]. Furthermore, Western patients are significantly more overweight, have a higher incidence of cardiovascular disease, and have a higher risk of thromboembolic complications. The proportion of proximal tumors is also increasing in the West, where total gastrectomy has been associated with twice the mortality of subtotal resection.

The present study has several limitations. The specific operative procedures and the extents of lymph node dissection may have stronger relationships with postoperative complications than does patient age. This study included patients with diverse operations and extents of nodal dissection. It is likely that the selected surgeries in the oldest old group were less invasive than the selected surgeries in the elderly group. Therefore, this study does not provide clear answers regarding the relationship between age and operative risk. In an attempt to decrease biases and clarify the risk factors for postoperative complications in oldest old patients, we divided these patients into those who did and did not experience complications. Subsequently, we compared the patients who actually did and did not experience complications in terms of the perioperative parameters that were associated with complications among all oldest old patients. We found that the groups did not differ significantly in terms of the operative procedures or the extent of lymph node dissection. A larger study with standardized and uniform procedures should be performed to validate our results. Nonetheless, the present study provides instructive background on surgical resections in oldest old patients with gastric cancer.

The overall survival rate after surgery was similar in both oldest and elderly patients, although limited lymph node dissections were performed more frequently in oldest 
old patients. There are several possible explanations for comparable surgical outcomes in the oldest old patients. Takeshita et al. [39] reported that surgical outcomes in elderly patients were comparable to those in nonelderly patients. They suggested that the biological behavior of the tumor (e.g., tumor growth and metastatic potential) may differ between elderly and young patients. Additionally, many of the elderly patients underwent at least limited lymph node dissection according to the Japanese guidelines [regional lymph node and Nos. 7, 8a, and $9(+11 \mathrm{p})]$. Takeshita et al. concluded that $\mathrm{R} 0$ resection with at least limited lymph node dissection (again, according to the Japanese guideline) should be considered as the treatment of first choice for elderly patients with gastric cancer, especially those between the ages of 80 and 84 years. The prognostic significance of radical surgical gastrectomy is still uncertain in oldest old patients (aged $\geq 85$ years) because relatively few cases are available for investigation. A future large study is required to confirm these findings.

In conclusion, preoperative serum albumin level and PNI are significant predictors of postoperative complications in oldest old patients (85 years old or older) with gastric cancer. In this late-stage elderly population, adjustments to the extent and invasiveness of surgeries and the degrees of lymphadenectomy are most likely to reduce the incidence of postoperative complications. When combined with evaluations of these nutritional parameters, preoperative risk assessments may allow more precise individual adjustments to surgical procedures.

Conflict of interest The authors declare no conflicts of interest.

\section{References}

1. Bureau S. Director-General for Policy Planning and Statistical Research and Training Institute. Handbook chapter 2, population. Available at: http://www.statgojp/english/data/handbook/c02conthtm. Accessed February 16, 2014.

2. Audisio RA, Veronesi P, Ferrario L, Cipolla C, Andreoni B, Aapro M. Elective surgery for gastrointestinal tumours in the elderly. Ann Oncol. 1997;8(4):317-26.

3. Page MJ, Poritz LS, Kunselman SJ, Koltun WA. Factors affecting surgical risk in elderly patients with inflammatory bowel disease. J Gastrointest Surg. 2002;6(4):606-13.

4. Onodera T, Goseki N, Kosaki G. Prognostic nutritional index in gastrointestinal surgery of malnourished cancer patients. Nihon Geka Gakkai Zasshi. 1984;85(9):1001-5.

5. Phoon RK. Chronic kidney disease in the elderly: assessment and management. Aust Fam Physician. 2012;41(12):940-4.

6. Copeland GP, Jones D, Walters M. POSSUM: a scoring system for surgical audit. Br J Surg. 1991;78(3):355-60.

7. Prytherch DR, Whiteley MS, Higgins B, Weaver PC, Prout WG, Powell SJ. POSSUM and Portsmouth POSSUM for predicting mortality. Physiological and Operative Severity Score for the enUmeration of Mortality and morbidity. $\mathrm{Br} \mathrm{J}$ Surg. 1998;85(9):1217-20.
8. Tekkis PP, Kocher HM, Bentley AJ, Cullen PT, South LM, Trotter GA, et al. Operative mortality rates among surgeons: comparison of POSSUM and p-POSSUM scoring systems in gastrointestinal surgery. Dis Colon Rectum 2000;43(11):1528-1532, discussion 32-34.

9. Tekkis PP, McCulloch P, Poloniecki JD, Prytherch DR, Kessaris $\mathrm{N}$, Steger AC. Risk-adjusted prediction of operative mortality in oesophagogastric surgery with O-POSSUM. $\mathrm{Br} \quad \mathrm{J}$ Surg. 2004;91(3):288-95.

10. Whiteley MS, Prytherch DR, Higgins B, Weaver PC, Prout WG. An evaluation of the POSSUM surgical scoring system. Br J Surg. 1996;83(6):812-5.

11. Yan J, Wang YX, Li ZP. Predictive value of the POSSUM, p-POSSUM, cr-POSSUM, APACHE II and ACPGBI scoring systems in colorectal cancer resection. J Int Med Res. 2011;39(4):1464-73.

12. Oken MM, Creech RH, Tormey DC, Horton J, Davis TE, McFadden ET, et al. Toxicity and response criteria of the Eastern Cooperative Oncology Group. Am J Clin Oncol. 1982; 5(6):649-55.

13. Ortega G, Rhee DS, Papandria DJ, Yang J, Ibrahim AM, Shore $\mathrm{AD}$, et al. An evaluation of surgical site infections by wound classification system using the ACS-NSQIP. J Surg Res. 2012;174(1):33-8.

14. Kelly KJ, Greenblatt DY, Wan Y, Rettammel RJ, Winslow E, Cho CS, et al. Risk stratification for distal pancreatectomy utilizing ACS-NSQIP: preoperative factors predict morbidity and mortality. J Gastrointest 2011;15(2):250-259, discussion 259-261.

15. Clavien PA, Barkun J, de Oliveira ML, Vauthey JN, Dindo D, Schulick RD, et al. The Clavien-Dindo classification of surgical complications: five-year experience. Ann Surg. 2009;250(2): 187-96.

16. Clavien PA, Strasberg SM. Severity grading of surgical complications. Ann Surg. 2009;250(2):197-8.

17. Dindo D, Demartines N, Clavien PA. Classification of surgical complications: a new proposal with evaluation in a cohort of 6336 patients and results of a survey. Ann Surg. 2004;240(2): 205-13.

18. Hayashi T, Yoshikawa T, Aoyama T, Ogata T, Cho H, Tsuburaya A. Severity of complications after gastrectomy in elderly patients with gastric cancer. World J Surg. 2012;36(9):2139-45.

19. Watanabe M, Iwatsuki M, Iwagami S, Ishimoto T, Baba Y, Baba $\mathrm{H}$. Prognostic nutritional index predicts outcomes of gastrectomy in the elderly. World J Surg. 2012;36(7):1632-9.

20. Tei M, Ikeda M, Haraguchi N, Takemasa I, Mizushima T, Ishii H, et al. Risk factors for postoperative delirium in elderly patients with colorectal cancer. Surg Endosc. 2010;24(9):2135-9.

21. Deiner S, Silverstein JH. Postoperative delirium and cognitive dysfunction. Br J Anaesth. 2009;103(suppl 1):i41-6.

22. Field RR, Wall MH. Delirium: past, present, and future. Semin Cardiothor Vasc Anesth. 2013;17(3):170-9.

23. Plaschke K, Fichtenkamm P, Schramm C, Hauth S, Martin E, Verch M, et al. Early postoperative delirium after open-heart cardiac surgery is associated with decreased bispectral EEG and increased cortisol and interleukin-6. Intensive Care Med. 2010;36(12):2081-9.

24. Whitson BA, Huddleston SJ, Savik K, Shumway SJ. Risk of adverse outcomes associated with blood transfusion after cardiac surgery depends on the amount of transfusion. J Surg Res. 2010;158(1):20-7.

25. Buzby GP, Mullen JL, Matthews DC, Hobbs CL, Rosato EF. Prognostic nutritional index in gastrointestinal surgery. Am J Surg. 1980;139(1):160-7.

26. Wakabayashi H, Sano T, Yachida S, Okano K, Izuishi K, Suzuki Y. Validation of risk assessment scoring systems for an audit of 
elective surgery for gastrointestinal cancer in elderly patients: an audit. Int J Surg. 2007;5(5):323-7.

27. Vaughan-Shaw PG, Rees JR, King AT. Neutrophil lymphocyte ratio in outcome prediction after emergency abdominal surgery in the elderly. Int J Surg. 2010;10(3):157-62.

28. Yamanaka H, Nishi M, Kanemaki T, Hosoda N, Hioki K, Yamamoto M. Preoperative nutritional assessment to predict postoperative complication in gastric cancer patients. JPEN J Parenter Enteral Nutr. 1989;13(3):286-91.

29. Otsuka Y, Kunisaki C, Ono H, Yamada R, Matsuda G, Nomura $\mathrm{M}$, et al. Modified POSSUM to predict postoperative morbidity following gastrectomy. Hepatogastroenterology. 2007;54(76): 1142-5.

30. Clarke A, Murdoch H, Thomas MJ, Cook TM, Peden CJ. Mortality and postoperative care after emergency laparotomy. Eur J Anaesthesiol. 2011;28(1):16-9.

31. Kodera Y, Sasako M, Yamamoto S, Sano T, Nashimoto A, Kurita A. Identification of risk factors for the development of complications following extended and superextended lymphadenectomies for gastric cancer. Br J Surg. 2005;92(9):1103-9.

32. Park DJ, Lee HJ, Kim HH, Yang HK, Lee KU, Choe KJ. Predictors of operative morbidity and mortality in gastric cancer surgery. Br J Surg. 2005;92(9):1099-102.

33. Cuschieri A, Fayers P, Fielding J, Craven J, Bancewicz J, Joypaul $\mathrm{V}$, et al. Postoperative morbidity and mortality after D1 and D2 resections for gastric cancer: preliminary results of the MRC randomised controlled surgical trial. The Surgical Cooperative Group. Lancet. 1996;347(9007):995-9.

34. Bonenkamp JJ, Songun I, Hermans J, Sasako M, Welvaart K, Plukker JT, et al. Randomised comparison of morbidity after D1 and D2 dissection for gastric cancer in 996 Dutch patients. Lancet. 1995;345(8952):745-8.

35. McCulloch P, Ward J, Tekkis PP, Surgeons AGO, British Oesophago-Gastric Cancer Group. Mortality and morbidity in gastro-oesophageal cancer surgery: initial results of ASCOT multicentre prospective cohort study. BMJ 2003;327(7425): $1192-1197$.

36. Pye JK, Crumplin MKH, Charles J, Kerwat R, Foster ME, Biffin A. One-year survey of carcinoma of the oesophagus and stomach in Wales. Br J Surg. 2001;88(2):278-85.

37. van Gestel YR, Lemmens VE, de Hingh IH, Steevens J, Rutten HJ, Nieuwenhuijzen GA, et al. Influence of comorbidity and age on 1-, 2-, and 3-month postoperative mortality rates in gastrointestinal cancer patients. Ann Surg Oncol. 2013;20(2):371-80.

38. Griffin SM. Gastric cancer in the East: same disease, different patient. Br J Surg. 2005;92(9):1055-6.

39. Takeshita H, Ichikawa D, Komatsu S, Kubota T, Okamoto K, Shiozaki A, et al. Surgical outcomes of gastrectomy for elderly patients with gastric cancer. World J Surg. 2013;37(12):2891-8. 